\title{
Vitamin and mineral intakes in European children. Is food fortification needed?
}

\author{
Lluís Serra-Majem* \\ Department of Clinical Sciences, University of Las Palmas de Gran Canaria, Spain
}

\begin{abstract}
Objective: To provide an overview of vitamin and mineral intakes among children and adolescents in European countries and to present results from studies showing the impact of food fortification.

Design: Comparative analysis of a number of nutritional studies among children and adolescents performed during the last decade in certain European countries.

Setting: Spain, France, UK, North Ireland, Portugal, Germany.

Subjects: Europeans aged 6 to 18.

Results: Dietary surveys across Europe showed that varying levels of nutrient adequacy existed from one country to another, and that even within the same country, there were important nutritional gaps between different regions. In general, studies are difficult to compare, and information for many countries was missing. The results suggest that children and adolescents are the population group most likely to have higher risk of nutritional deficiencies, particularly for iron, vitamins $\mathrm{C}$, $\mathrm{E}, \mathrm{B}_{6}$ and folates. In France, Ireland, UK and Spain, food fortification, and particularly of breakfast cereals, has positively contributed to increasing vitamin and mineral intakes in childhood and adolescence.

Conclusions: Information on vitamin and mineral intakes in European children is less available than in adults. Fortified foods may contribute to reducing nutrient inadequacy in European children and adolescents, but should not replace nutrition education.
\end{abstract}

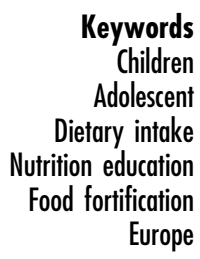

\section{Introduction}

A varied and balanced diet should provide adequate amounts of all nutrients. A (marginally) deficient intake may arise when food choices result in an unbalanced diet, if the diet is naturally poor in specific nutrients, if a nutrient is removed during processing, handling or storage, or if, because of physiological conditions, requirements are increased. Policy instruments to improve nutrient intake of a population or population groups are nutrition education, fortification and recommendation of the use of supplements ${ }^{1,2}$.

The intake of nutrients among European children typically varies widely and will range from low and inadequate, sufficient or optimal, to high possibly excessive intakes (which does not necessarily indicate toxicity). According to differences in dietary habits and food consumption between regions and countries, the nutritional status of European children varies considerably from north to south and from east to west. In certain European countries, particularly in Nordic and Western regions, nutrient supplementation and food fortification have become very popular, but they are less frequent in
Southern and Eastern countries ${ }^{3,4}$. The addition of vitamins, minerals and trace elements to foods can increase the intake of these nutrients in (segments of) the population. This may reduce the risk of inadequate intakes and also decrease the risk of certain diseases and conditions. To gain insight into the possible benefits of adding vitamins, minerals and trace elements to foodstuffs it is necessary to know the current situation with regard to inadequate or low intakes ${ }^{5,6}$.

\section{Assessment of nutrient intake in childhood and adolescence across Europe}

The evaluation of nutritional status in children and adolescents incurs certain complications compared to that of adults. Firstly, though other methods of estimating food bioavailability such as Food Balance Sheets or Household Budget Surveys can provide an acceptable estimate of the nutritional situation of a population, they are inadequate for evaluations of age-specific groups (such as in children and adolescents). Therefore, it is necessary to conduct individual surveys based on representative samples of the population. Secondly, 
carrying out food surveys in children is more complex, particularly for those 12 years or younger where adult collaboration is required. Thirdly, the great diversity of foods consumed in childhood and the continuous appearance of new food products make it necessary to continuously revise and update food composition tables. Finally, greater frequency of snacking also increases the complexity of determining food intakes. An advantage of childhood food surveys is that schools may be utilised as interview sites and units for sample stratification for carrying out diet interviews. However, diverse studies show greater validity in interviews conducted in the homes of those interviewed ${ }^{7-9}$.

In Europe there have been few national nutrition surveys carried out in childhood and adolescence. Recent reviews of dietary habits and nutritional status of European youth reflect the following conclusions:

Nordic countries periodically carry out national surveys on representative samples of children and adolescents. On average, dietary calcium intake more than meets requirements, whereas the intakes of fibre, vitamin $\mathrm{D}$, zinc and selenium and, in girls, iron, are below the recommended nutrient intakes $(\mathrm{RNI})^{10}$.

In Southern Europe the information is scarce and, with the exception of Portugal, the data is very local and/or obtained from small samples. A risk of deficiency has been detected for calcium, iron and zinc, and also for vitamin $\mathrm{A}$ and vitamin $\mathrm{E}^{11}$. Recently completed is the ENKID (feeding habits and nutritional status in Spanish children and adolescents) study in Spain, a comprehensive evaluation of nutritional status of the population aged 6 to 24 years $^{12}$. This will provide further data on this region.

In Central and Eastern Europe, the small number of studies and inadequate sample size do not allow for drawing conclusions in this area, but insufficient calcium, fibre and vitamin $\mathrm{C}$ intakes seem evident ${ }^{13}$.

In Western Europe more complete information is available, particularly in the United Kingdom, Ireland, France and the Netherlands. Calcium and iron seem to be the problem nutrients ${ }^{14}$.

One of the objectives of this article is to analyse detailed information from several dietary surveys conducted in Europe. The difficulty of comparing results due to differing dietary survey methods and target age groups presents major problems in this regard. Table 1 shows the results from five countries ${ }^{15-19}$. In general, the intakes of vitamin $\mathrm{C}$, thiamine and vitamins $\mathrm{A}$ and $\mathrm{E}$ are greater in Spain and Portugal. Among the female population a higher intake of folate and iron is noted as compared to the UK. Calcium intakes appear similar across the five countries, although a high intake is seen among females in Spain compared with females in the remaining four populations.

Within the same country there can be significant regional differences in nutrient intake. For example, in

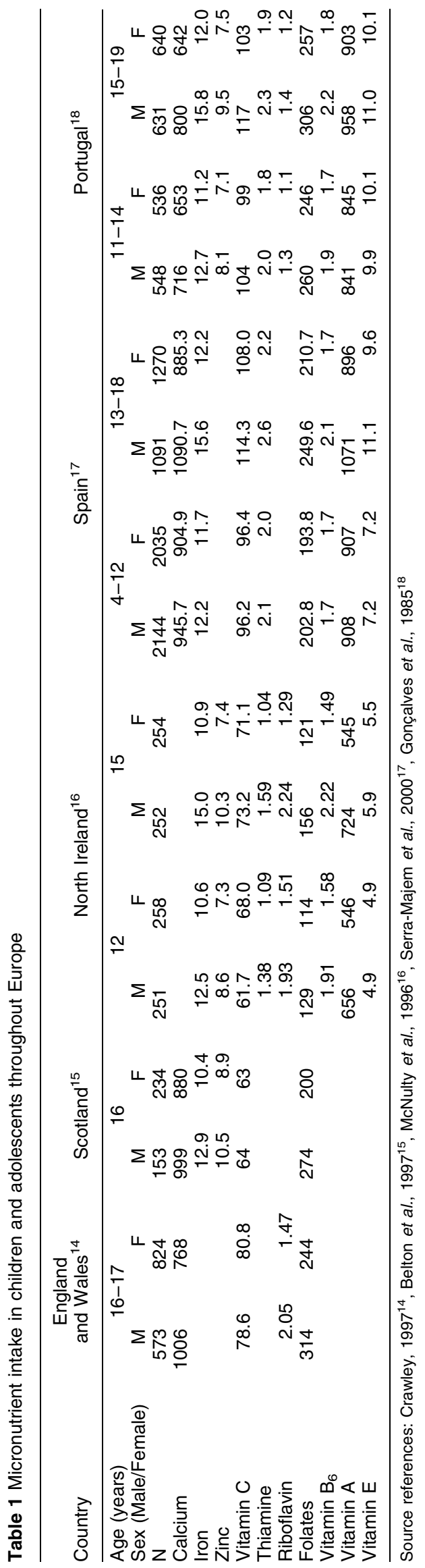


Table 2 Micronutrient intake at different ages in Catalonia (1992-93) and Canary Islands (1997-98), Spain

\begin{tabular}{|c|c|c|c|c|c|c|c|c|c|c|c|c|}
\hline & \multicolumn{4}{|c|}{$6-18$ years } & \multicolumn{4}{|c|}{$35-45$ years } & \multicolumn{4}{|c|}{$65-75$ years } \\
\hline & \multicolumn{2}{|c|}{$\begin{array}{c}\text { Catalonia } \\
(n=424) \\
x\end{array}$} & \multicolumn{2}{|c|}{$\begin{array}{l}\text { Canary Islands } \\
(n=428) \\
\mathrm{X}\end{array}$} & \multicolumn{2}{|c|}{$\begin{array}{c}\text { Catalonia } \\
(n=464) \\
x\end{array}$} & \multicolumn{2}{|c|}{$\begin{array}{c}\text { Canary Islands } \\
(n=281) \\
\mathrm{X}\end{array}$} & \multicolumn{2}{|c|}{$\begin{array}{c}\text { Catalonia } \\
(n=249) \\
x\end{array}$} & \multicolumn{2}{|c|}{$\begin{array}{c}\text { Canary Islands } \\
(n=164) \\
\text { X }\end{array}$} \\
\hline & Men & Women & Men & Women & Men & Women & Men & Women & Men & Women & Men & Women \\
\hline Calcium (mg) & 869.4 & 783.9 & 1002.1 & 881.8 & 734.6 & 762.1 & 963.2 & 78 & 670.4 & 743.6 & 841.6 & 83 \\
\hline Iron (mg) & 13.8 & 11.8 & 13.0 & 10 & 14.4 & 11.8 & 13.4 & 9.8 & 12.8 & 10.2 & 12.0 & 9.5 \\
\hline m (mg) & 315.5 & 280.9 & 303.1 & 261.4 & 318.9 & 271.2 & & & 304.0 & 257.7 & 287.5 & 41.1 \\
\hline Thia & 1.41 & 1.22 & 1.22 & & 1.28 & 1.07 & 1.20 & & 1.12 & 0.99 & 1.03 & 0.94 \\
\hline Ribo & 1.80 & 1.61 & 1.83 & 1.6 & 1.64 & 1.55 & 1.81 & 1.70 & 1.45 & 1.47 & 1.70 & 1.81 \\
\hline Niaci & 19.9 & 17.9 & 20.8 & 18.3 & 21.2 & 18.3 & 25.7 & 19.8 & 19.1 & 16.3 & 21.0 & 18.9 \\
\hline Folate & 284.9 & 259.5 & 148.4 & 128.6 & 325.2 & 317.3 & 168.3 & 145.9 & 349.7 & 301.3 & 161.5 & 148.5 \\
\hline Vitamin $\mathrm{B}_{12}(\mu \mathrm{g})$ & 5.9 & 6.0 & 6.81 & 4.33 & 8.2 & 6.8 & 6.40 & 4.53 & 7.2 & 6.0 & 5.55 & 3.68 \\
\hline Vitam & 88.1 & 79.6 & 76.9 & 63.5 & 101.0 & 112.2 & 89.6 & 80.0 & 121.1 & 113.6 & 107.2 & 104.1 \\
\hline Vita & 3.3 & 2.5 & 3.06 & 2.34 & 4.8 & 3.3 & 2.77 & 1.76 & 4.3 & 3.0 & 1.87 & 1.51 \\
\hline$A(\mu g)$ & 987.9 & 1050.6 & 652.6 & 533.3 & 1161.4 & 1434.7 & 631.4 & 592.8 & 1282.5 & 1035.9 & 552.7 & 628.2 \\
\hline Vitamin $B_{6}(\mathrm{mg})$ & 1.88 & 1.67 & 1.65 & 1.41 & 1.91 & 1.64 & 1.86 & 1.48 & 1.77 & 1.53 & 1.76 & 1.55 \\
\hline Vitamin $E(\mathrm{mg})$ & 8.77 & 8.32 & 6.52 & 5.82 & 9.82 & 8.57 & 6.45 & 5.64 & 9.20 & 7.40 & 5.31 & 5.71 \\
\hline
\end{tabular}

Sources: Serra-Majem et al., $1996^{19}$ and $2000^{20}$.

Spain, folate consumption in Catalonia is double that of the Canary Islands ${ }^{20,21}$, along with greater intakes of Vitamin A. However, calcium consumption is higher in the Canary Islands (Table 2). In addition, consumption of certain vitamins (e.g. folate and vitamins $\mathrm{B}_{12}$ and $\mathrm{C}$ ) improves with age. The same methodology was utilised in both studies, thus making the comparison of results more reliable. This underscores the necessity of harmonising study methodologies of food and nutrition surveys in Europe.

The results suggest that children and adolescents are a population group likely to have higher risks of vitamin deficiencies. Also, despite their higher caloric intake, compared to adults these age groups are more prone to suffering inadequate intakes of iron, vitamin $\mathrm{C}$, vitamin $\mathrm{E}$, vitamin $\mathrm{D}$, folate and vitamin $\mathrm{B}_{6}{ }^{19-22}$.

\section{Dietary guidelines and nutrition education in childhood}

The development of dietary guidelines for children and adolescents, nutrition education programs in schools and the family environment constitute the pillars for promoting healthy nutrition in childhood. Within the context of nutrition education, certain factors may act as obstacles in the creation of dietary guidelines for a healthy population. These are summarised in the following five points:

1. For certain nutrients (such as folate and Vitamin D) the RNI are difficult to obtain through consumption of conventional foods. Numerous examples demonstrate this; for example, the RNI for calcium, which was originally $500 \mathrm{mg}$ following the FAO-WHO recommendations, has been increased to more than $1 \mathrm{~g}$ by a number of committees. This change is directed towards a concept of osteoporosis prevention rather than only optimal growth and physical development, whilst acknowledging that the body's maximum calcium retention is $400 \mathrm{mg} /$ day. Another example can be seen in folic acid and elevated homocysteine levels and cardiovascular risk. Supplements of $0.4 \mathrm{mg}$ of folic acid ( $0.8 \mathrm{mg}$ of folate) were generally sufficient to reduce or normalise elevated homocysteine levels, even if these were not a result of inadequate folate intake (less than $200 \mu \mathrm{g}$, according to the classic RNI). In many countries it is difficult to increase dietary folate consumption to the levels which would reduce cardiovascular risk and prevent neural tube defects ${ }^{5,6}$.

2. The reduction of energy intake which has occurred in the majority of industrialised countries in parallel with reduced physical activity leads to the need for increased nutrient density in the diet.

3. Many populations, such as the Spanish or other Mediterranean regions ${ }^{23}$, exhibit dietary habits that are considerably healthy, which, in their entirety are difficult to improve through nutrition education. Increasing intakes from certain food groups (for example dairy products) may result in decreased consumption of other groups (such as fruits), and thus, would not necessarily indicate improved health status. Although it has been demonstrated that improving food habits and diversity reduces vitamin deficiency risk, deficits can still occur in relatively favourable conditions. For example, in Spain, Greece and Portugal, fruit and vegetable consumption is clearly higher than in Northern European countries, resulting in greater intakes of folate, carotenes and vitamin C. However, retinol consumption is lower due to lower intakes of meat and dairy products and animal fats. If vitamin A intake were increased through nutrition education efforts, it is likely that consumption of foods rich in other vitamins and minerals would be reduced as, quite often, the margin of available manoeuvrability is scarce. In any case, differences between countries are less acute when comparing child and adolescent populations versus adult comparisons, as greater homogeneity exists among European youth.

4. Social services are typically overloaded with demands. However many of the problems faced are not produced by medically related issues and could be resolved by 
Table 3 Advantages and disadvantages of supplementation and fortification

\begin{tabular}{lll}
\hline & Nutritional Supplementation & Nutrient Fortification \\
\hline Advantages & Greater specificity in the intervention & Universal \\
& - Better dose adjustment & Greater compliance \\
Disadvantages & - Incurred user cost & - Lo a function of food quantity consumed \\
& - Low compliance & - Varying standards legislated for each country \\
& - Increased risk of toxicity & \\
\hline
\end{tabular}

Source: Serra-Majem and Aranceta, $2000^{25}$.

adequate social approaches. Educators are overwhelmed with tasks and teaching responsibilities and thus, have little time for nutrition education. Moreover, there is a lack of incentive and motivation for the promotion of healthy eating, which is especially evident in Southern European countries, as government officials trust in the goodness of the Mediterranean diet or remain unaware of the dietary changes that have taken place ${ }^{24}$.

5. There are often difficulties in reaching consensus for the development of food guides for a healthy population. This may be due to the varying interests that each participating scientific association has in relation to 'their particular disease' and nutrition (calcium sources would be the priority for osteoporosis specialists, dietary fats for cardiologists, fruits and vegetables for oncologists, supplements in the case of obstetricians, infant formula for paediatricians, to cite some examples). All this highlights the importance and responsibility of Nutrition Societies in their role of consensus building among scientific societies of other disciplines towards this end.

\section{Fortified foods or supplements?}

In general, nutrient supplementation and fortification are utilised for the following purposes:

- To help ensure that a population's daily intake of vitamins and minerals meet the RNIs, when intake from unfortified foods do not reach the recommended levels.

- To provide levels of vitamins, minerals and trace elements greater than the current RNIs if there has been a demonstrated benefit against the manifestation of disease in healthy individuals or in the progression of a pre-existing disease in affected persons

The advantages and disadvantages of nutrient supplementation versus fortification is shown in Table $3^{25}$. Globally, when speaking in terms of prevention, there are four levels in which community nutrition plays a role:

1. The objective of Primordial Prevention is to improve the health status of a population. Nutrition education may play a fundamental role at this level of health promotion because an overall improvement in dietary habits results in improved health and quality of life. Food fortification may also contribute to improved consumer health.

2. Primary Prevention consists of risk reduction for a given disease and could be taken on via nutrition education and nutrient fortification as a mass strategy at the population level. Here, food fortification has a greater role because its action should be spread throughout the population and requires continuity.

3. Secondary Prevention deals with the early detection and treatment of diseases. Nutrition supplements and nutrition education could be targeted towards high risk individuals.

4. Tertiary Prevention consists of reducing disease-related complications. It would involve the use of nutrition education and nutrition supplements with patients.

In order for programs to be effective, the perceptions and attitudes of the population towards nutrition education and supplementation should be analysed. Very often supplementation is perceived as an additional health risk caused by possible problems with toxicity described for certain vitamins and minerals. For this reason it is necessary to keep in mind the potential health risk that an excess intake of a nutrient could represent ${ }^{26,27}$. However in practice this risk is greater with supplements rather than enriched foods. The risk of toxicity is quite low and almost non-existent when levels equal to or less than the RNIs are applied as criteria for fortification or supplementation. The upper limit of safe intake exceeds, for the majority of nutrients, 10 times the recommended values $^{26}$

\section{Food fortification: the case of breakfast cereals}

There are many foods to which the addition of vitamins and minerals has contributed to improved intake and nutritional status. Perhaps the most representative example is seen in the ready to eat breakfast cereals (RTEC).

Many of the advantages to a population's health of consuming a complete breakfast have attributed the inclusion of RTEC as part of this meal ${ }^{28}$. The analysis of RTEC consumption supports this concept. A recent study in France has described the association between having a complete, balanced breakfast and including RTEC $^{29}$. In a country such as the United Kingdom, which has a long tradition of consuming these products, RTEC intake has contributed to considerable improvement in the consumption of specific nutrients in the last 50 years $^{30}$. As such, the main sources of iron in 1950 came primarily from bread (2.25 mg/day), meat ( $1.6 \mathrm{mg} /$ day), vegetables $(0.9 \mathrm{mg} /$ day) and other cereals $(0.8 \mathrm{mg} /$ day $)$, whereas RTEC provided $0.5 \mathrm{mg} /$ day. In 1992-93 RTEC contributed $1.3 \mathrm{mg}$ of iron/day and constituted the main source of 
Table 4 Impact of fortification on the diets of North Irish children. Proportion of children with intakes below the lower nutrient reference intake (LNRI)

\begin{tabular}{lcccc}
\hline \multicolumn{4}{c}{ Breakfast cereal consumption (grams per day): girls $12 \mathrm{yr}$} \\
\hline & 0 & $1-20$ & $20-40$ & $>40$ \\
& $(n=31)$ & $(n=67)$ & $(n=106)$ & $(n=34)$ \\
Thiamine & $35 \%$ & $3 \%$ & $0 \%$ & $0 \%$ \\
Riboflavin & $13 \%$ & $3 \%$ & $1 \%$ & $1 \%$ \\
Niacin & $10 \%$ & $0 \%$ & $0 \%$ & $0 \%$ \\
Folate & $94 \%$ & $93 \%$ & $93 \%$ & $76 \%$ \\
Iron & $35 \%$ & $22 \%$ & $13 \%$ & $11 \%$ \\
\hline
\end{tabular}

LRNI=The amount of nutrient estimated to be sufficient for only $2.5 \%$ of the population

ANOVA with LSD test. $P<0.001$

Source: McNulty et al. $1996^{16}$

dietary iron, followed by meat $\left(0.8 \mathrm{mg} /\right.$ day). Gibson ${ }^{31}$, in a study on British schoolchildren aged 1.5 to 4.5 years concluded that: 'high cereal consumers had significantly higher iron intakes than low cereal consumers, but low intakes of vitamin $\mathrm{C}$ and meat. Nutrition advice that aims to improve iron status should emphasize not only rich sources of iron but also factors that may enhance or inhibit absorption. Strategies to optimize iron status in this group include consuming an iron-fortified RTEC and vitamin C-rich fruit for breakfast, and avoiding tea'. Furthermore, McNulty et al. ${ }^{17}$ found that Irish children who never consumed fortified breakfast cereals generally had adequate mean nutrient intakes. However, a significant proportion of such girls had intakes below the lower RNI for riboflavin, niacin, folate, vitamin $\mathrm{B}_{12}$ or iron, indicating a severely increased risk of physiological deficiency (Table 4). Finally, in German children and adolescents, fortification of food with vitamin $\mathrm{E}$ and folic acid improved the inadequate intake of these vitamins. However, for iron, fortification levels seemed insufficient. For other nutrients such as vitamins $\mathrm{A}, \mathrm{C}, \mathrm{B}_{1}, \mathrm{~B}_{2}, \mathrm{~B}_{6}$ and niacin, fortification appeared unnecessary ${ }^{32}$.

Many studies have clearly demonstrated that for children and adolescents who regularly consumed RTEC, there is an improvement in carbohydrate, fibre and numerous vitamin and mineral intakes, with certain nutrients showing significant increases. Moreover, less obesity and overweight are seen in children and adolescents who routinely eat cereal for breakfast. This effect was notable even when calories and nutritional quality (expressed as the number of basic foods included) of breakfast foods were controlled for ${ }^{33,34}$.

Nevertheless, a low mean population intake relative to the RNIs does not necessarily demonstrate low status or deficiency. Studies with the addition of calcium citrate malate as a soluble source of calcium in fruit drinks, have shown significantly increased bone mass in prepubescent girls $^{35,36}$, although in general the effect of calcium intake on bone density is complex and the results are contradictory. RTEC may also be calcium enriched. In a French study by Preziosi et al. ${ }^{29}$, consumers of fortified breakfast cereals had improved biological status compared with non-consumers, for vitamins B1, B2 and folic acid. Additionally, Cuskelly et al. ${ }^{37}$, showed that withdrawing folic acid from fortified foods in the diets of Irish women over a 3 month period led to a highly significant fall in red cell and serum folate (from $370 \mu \mathrm{g}$ to $250 \mu \mathrm{g} / \mathrm{L}$ and from $8.4 \mu \mathrm{g}$ to $5.9 \mu \mathrm{g} / \mathrm{L}$ respectively). In a separate intervention study, folic acid fortified foods or dietary supplements were more effective at raising red cell folate than dietary advice increasing fruit and vegetable consumption $^{38}$

Without a doubt one can see the clear example of how an enriched food can contribute to improving the health status of a population that consumes it, and thus is of great interest to nutrition and public health experts. This could be especially relevant for folate, given the risk of unplanned pregnancies in this age range and its role in the reduction of neural tube defects, and also for other nutrients such as iron, calcium, Vitamin D or thiamine. In terms of calorie levels and obesity, the effect of RTEC on fat consumption at breakfast and throughout the day is also quite significant, as the greatest RTEC consumers have calorie and fat intakes nearer to recommended intakes, and showed less prevalence of obesity.

Obviously, these observed effects may not be exclusively attributable to RTEC consumption alone. Factors influencing intake of other foods also exist which could be related to cereal consumption (for example, dairy products or fruit). As such, it is an indication that a certain feeding and cultural pattern associated with RTEC consumption exists in Europe, which would be necessary to analyse in greater detail.

\section{Final considerations}

Health professionals are the preferred source of information for the population at large. For this reason the role of doctors, pharmacists, nurses and dietitians in nutrition education must be highlighted. Contact between professionals and the public should be effectively utilised to transmit dietary and nutritional messages that are considered high priority ${ }^{39}$. In the case of supplements, and given that these are mainly bought in pharmacies ( $80 \%$ in Spain or Italy, versus $60 \%$ in Great Britain for example ${ }^{40}$ ), pharmacists can play a decisive role in the appropriate use of supplements by the general public. Schools constitute a fundamental base for nutrition education during childhood. Solid political support is required as well in order to carry out school programmes that are effective and have continuity ${ }^{41}$. Governments should provide incentives for realising nutrition education programmes in schools and in primary health care settings.

Identification of nutritionally at-risk groups and the orientation of fortified foods and programmes of supplementation in these populations is a necessary strategy to be coherent. In this sense, it might be said that food fortification has reduced the seriousness of certain 
nutritional problems from a public health perspective (e.g. folic acid, vitamin D, iron). In particular, RTEC have positively contributed to increasing folic acid, iron and other vitamin intakes and nutritional status in infant and adolescent populations in France, Ireland, UK, Spain and other European countries.

More research is needed in those countries where food fortification is less widespread and where they have traditionally been consuming a balanced diet, such as the European Mediterranean countries. This would shed light on the effects on health status of food fortification among children, who are undergoing important changes in their traditional food habits.

Community nutrition interventions should take place within the context of food availability and nutrition education as their principal approach. They should also be in accordance with food guides and, whenever the circumstances are called for, with fortification of foods and, eventually, supplementation. Such interventions should be adequately planned and evaluated within the context of each country or region.

\section{Acknowledgements}

The author acknowledges Lourdes Ribas, MD, and Joy Ngo, RD, from the Centre of Community Nutrition Research at the Science Park of the University of Barcelona, for their editing support and supervision of the English version.

\section{References}

1 Blumberg JB, Public Health implications of preventive nutrition. In: Bendich A, Dechelbaum RJ, eds. Preventive nutrition. Totowa: Humana Press, 1997: 1-16.

2 Hercberg S, Galan P, Preziosi P, Alfarez MJ, Vazquez C. The potential role of antioxidant vitamins in preventing cardiovascular disease and cancers. Nutrition 1998; 14: 513-20.

3 Gassin AL. Fortification and the European consumer: consumer awareness and attitudes to food fortification. Scan. J. Nutr. 1999; 43 (Suppl 35): 122S-4S.

4 Peetz-Schou M. Nordic legislative practices and consumer attitudes towards the addition of nutrients to foods. Scan.J. Nutr. 1999; 43 (Suppl 35): 125S-8S.

5 Pietrzik K. Optimal intake of micronutrients for health and well-being. New perspectives in the definition of RDAs. Scan. J. Nutr. 1999; 43 (Suppl 35): 101S-5S.

6 McNulty H. Towards improving dietary intakes and health: the contribution of fortified foods. Scan. J. Nutr. 1999; 43 (Suppl 35): 106S-11S.

7 Persson LA, Carlgren G. Measuring children's diets: evaluation of dietary assessment techniques in infancy and childhood. Int. J. Epidemiol. 1984; 13: 506-17.

8 Trebier FA, Leonard SB, Frank G, Musante L, Davis H, Strong WB. et al. Dietary assessment instruments for preschool children: reliability of parental responses to the 24-hour recall and food-frequency questionnaire. J. Am. Diet. Assoc. 1990; 90: 814-20.

9 García Closas R, Serra Majem L. Encuestas alimentarias en la infancia (in press).

10 Samuelson G. Dietary habits and nutritional status in adolescents over Europe. An overview of current studies in the Nordic countries. Eur. J. Clin. Nutr. 2000; 54 (Suppl 1): S21-8.

11 Armorin Cruz JA. Dietary habits and nutritional status in adolescents over Europe. Southern Europe. Eur. J. Clin. Nutr. 2000; 54 (Suppl 1): S29-S35.

12 Serra Majem Ll, Aranceta Bartrina J, eds. Desayuno $y$ equilibrio alimentario Estudio Enkid. Barcelona: Masson, 2000.

13 Parízková J. Dietary habits and nutritional status in adolescents in Central and Eastern Europe. Eur. J. Clin. Nutr. 2000; 54 (Suppl 1): S36-40.

14 Rolland-Cachera M-F, Bellisle F, Deheeger M. Nutritional status and food intake in adolescents living in Western Europe. Eur. J. Clin. Nutr. 2000; 54 (Suppl 1): S41-6.

15 Crawley H. Dietary and lifestyle differences between Scottish teenagers and those living in England and Wales. Eur.J. Clin. Nutr. 1997; 51: 87-91.

16 Belton NR, Macvean ADL, Richards ND, Elton RA, Moffat WMU, Beattie TF. Nutrient intake in Scottish adolescents. Proc. Nutr. Soc. 1997; 56: 303A.

17 McNulty HM, Eaton-Evans J, Cran G, Woulahan G, Boreham C, Savage JM. et al. Nutrient intakes and impact of fortified breakfast cereals in schoolchildren. Arch. Dis. Child. 1996; 75: 474-81.

18 Serra-Majem L, Ribas L, Ngo J, Aranceta J, Garaulet M, Marin $\mathrm{E}$, et al. Risk of inadequate intake for vitamin $\mathrm{A}, \mathrm{B}_{1}, \mathrm{~B}_{6}, \mathrm{C}, \mathrm{E}$, folate, iron and calcium in Spanish children (in press).

19 Gonçalves Ferreira FA, Armorin-Cruz JA, Aguilar LAR, Martins I, Mano MC, Dantas MA. Inquérito alimentar nacional 1980 ( $1^{\mathrm{a}}$ parte). Rev. Centro Estudos Nutriçào. 1985; 9: $5-$ 121.

20 Serra-Majem L, Ribas L, García Closas R, Ramon JM, Salvador G, Farran A. et al. Llibre Blanc: Avaluació de l'estat nutricional de la població catalana (1992-93). Barcelona: Departament de Sanitat i Seguretat Social, Generalitat de Catalunya, 1996: 1-252.

21 Serra-Majem L, Ribas Barba L. Armas Navarro A. Equipo investigador de ENCA 1997-98. Encuesta Nutricional de Canarias 1997-98. Ingesta de energia y nutrientes y riesgo de ingestas inadecuadas. Fuentes alimentarias de energia y nutrientes (Volumen 3). Santa Cruz de Tenerife: Servicio Canario de Salud, 2000.

22 Hercberg S, Preziosi P, Galan P, Deheeger M, Papoz L, Dupin H. Apports nutritionnels d'un échantillon représentatif de la population du Val-de-Marne: III. Les apports en minéraux et vitamines. Rev. Epidém et Santé Publ. 1991; 39: 245-61.

23 Serra-Majem L, Santana JF, Salmona E. Dietary habits and nutrient status in Spain. World Rev. Nutr. Diet. 2000; 87: 127-59.

24 Serra-Majem L, Ferro-Luzzi A, Bellizzi M, Salleras L. Nutrition policies in Mediterranean Europe. Nutr. Rev. 1997; 55: S42-57.

25 Serra-Majem L, Aranceta J. Guías alimentarias, educación nutricional, fortificación y suplementación. In: Galvez R, Sierra A, Saenz C, Gomez I, Fernández-Crehuet J, Salleras Led. Medicina Preventiva y Salud Pública (10 ed). Barcelona: Masson, 2000.

26 Van den Berg H. Responding to consumer needs: risk-benefit analysis of fortification. Scand. J. Nutrition. 1999; 43: 112S$6 \mathrm{~S}$.

27 Thelle DS. Fortification of food with nutrients, an effective way to promote public health? Scand. J. Nutrition. 1999; 43 $117 \mathrm{~S}-8 \mathrm{~S}$.

28 Ruxton CHS, Kirk TR. Breakfast: a review of associations with measures of dietary intake, physiology and biochemistry. $\mathrm{Br}$. J. Nutr. 1997; 78: 199-213.

29 Preziosi P, Galan P, Deheeger M, Yacoub N, Drewnowski A, Hercberg $S$. Breakfast type, daily nutrient intakes and vitamin and mineral status of French children, adolescents and adults. J. Am. Coll. Nutr. 1999; 18: 171-8.

30 Prynne CJ, Paul AA, Price GM, Day KC, Hildre WS, Wadsworth ME. Food and nutrient intake of a national 
sample of 4-year-old children in 1950: comparison with the 1990s. Public Health Nutr. 1999; 2: 537-47.

31 Gibson SA. Iron intake and iron status of preschool children: associations with breakfast cereals, vitamin $\mathrm{C}$ and meat. Public Health Nutr. 1999; 2: 521-8.

32 Sichert-Hellert W, Kersting M, Alexy U, Manz F. Ten-years trends in vitamin and mineral intake from fortified food in German children and adolescent. Eur. J. Clin. Nutr. 2000; 54: 81-6.

33 Serra-Majem L, Ribas L, Pérez C, Aranceta J. Cereales de desayuno y estado nutricional: Contribución de los cereales del desayuno a la nutrición de los niños y jóvenes españoles. In: Serra-Majem L, Aranceta Jed. Desayuno y equilibrio alimentario. Barcelona: Masson, 2000.

34 Ortega RM, Requejo AM, Redondo R, Lopez-Sobaler AM, Andres P, Ortega A. et al. Influence of the intake of fortified breakfast cereals on dietary habits and nutritional status of Spanish schoolchildren. Ann. of Nutr. Metab. 1996; 40: $146-56$.

35 Johnson CC, Miller JZ, Slemenda CW, Reister TK, Hui S, Christian JC, Peacock M. Calcium supplementation and increases in bone mineral density in children. New Eng. J. Med. 1992; 327: 82-7.
36 Lloyd T, Andon MB, Rollings N, Martel JK, Landis JR, Demers LM. et al. Calcium supplementation and bone mineral density in adolescent girls. J. Am. Med. Assoc. 1993; 270: 841-4.

37 Cuskelly GJ, McNulty H, McCullough F, Scott JM. The exclusion of folic-fortified foods significantly reduces folate status. Proc. Nutr. Soc. 1994; 53: 265A.

38 Cuskelly GJ, McNulty H, Scott JM. Changes in folate status in response to pteroylglutamic (folic) acid supplements, folic acid-fortified foods, food folate and dietary advice. Proc. Nutr. Soc. 1995; 54: 196A.

39 Serra-Majem L, Calvo JR, Malé ML, Ribas L, Lainez P. Population attitudes towards changing dietary habits and reliance on general practitioners in Spain. Eur. J. Clin. Nutr. 1999; 53 (Suppl 2): S58-S61.

40 Serra-Majem L, Ribas L, Sáiz de Bustamante P, López Blanco F, Barbachano M. Consumo de suplementos vitamínicominerales en la población española. Nutr. Clin. 1996; 16: $179-87$.

41 Aranceta Bartrina J, Pérez Rodrigo C. Consumo de alimentos $y$ estado nutricional de la población de Bilbao. Guías nutricionales para la población escolar. Bilbao: Área de Salud y Consumo. Excmo. Ayuntamiento de Bilbao, 1996. 